\title{
Evaluation of strain and stress states in the single point incremental forming process
}

\author{
D. M. Neto ${ }^{1}$ - J. M. P. Martins ${ }^{1}$ - M. C. Oliveira ${ }^{1}$ - L. F. Menezes ${ }^{1}$ - J. L. Alves $^{2}$
}

Received: 8 September 2015 / Accepted: 8 October 2015 /Published online: 17 October 2015

(C) Springer-Verlag London 2015

\begin{abstract}
Single point incremental forming (SPIF) is a promising manufacturing process suitable for small batch production. Furthermore, the material formability is enhanced in comparison with the conventional sheet metal forming processes, resulting from the small plastic zone and the incremental nature. Nevertheless, the further development of the SPIF process requires the full understanding of the material deformation mechanism, which is of great importance for the effective process optimization. In this study, a comprehensive finite element model has been developed to analyse the state of strain and stress in the vicinity of the contact area, where the plastic deformation increases by means of the forming tool action. The numerical model is firstly validated with experimental results from a simple truncated cone of AA7075-O aluminium alloy, namely, the forming force evolution, the final thickness and the plastic strain distributions. In order to evaluate accurately the through-thickness gradients, the blank is modelled with solid finite elements. The small contact area
\end{abstract}

D. M. Neto

diogo.neto@dem.uc.pt

J. M. P. Martins

joao.pmartins@dem.uc.pt

M. C. Oliveira

marta.oliveira@dem.uc.pt

L. F. Menezes

luis.menezes@dem.uc.pt

J. L. Alves

jlalves@dem.uminho.pt

1 CEMUC, Department of Mechanical Engineering, University of Coimbra, Polo II, Rua Luís Reis Santos, Pinhal de Marrocos, 3030-788 Coimbra, Portugal

2 MEMS, Microelectromechanical Systems Research Unit, University of Minho, Campus de Azurém, 4800-058 Guimarães, Portugal between the forming tool and the sheet produces a negative mean stress under the tool, postponing the ductile fracture occurrence. On the other hand, the residual stresses in both circumferential and meridional directions are positive in the inner skin of the cone and negative in the outer skin. They arise predominantly along the circumferential direction due to the geometrical restrictions in this direction.

Keywords Incremental forming · Finite element method . Forming forces $\cdot$ Formability $\cdot$ Twisting $\cdot$ Strain and stress fields

\section{Introduction}

The conventional sheet metal forming processes are commonly used for mass production, allowing sharing of the high cost of the forming tools among a large number of products. On the other hand, small batch production and rapid prototyping of sheet metal parts require the development of new production methods suitable for low series production [1]. In fact, nowadays, the sheet metal market demands more individuality and customer-specific products. Accordingly, the incremental sheet forming (ISF) process has received a considerable attention in the last years $[2,3]$. The plastic deformation is incrementally imposed locally by a small tool with a hemispherical head that follows a prescribed tool path. This forming process allows the manufacture of complex sheet parts without any expensive set of tools with specified shape or high capacity press machine, while the tool path can be automatically generated from the computer-aided design (CAD) file of the part to be formed. Therefore, the process is very flexible and can be carried out on a computer numerical control $(\mathrm{CNC})$ milling machine, robots or specially designed machines [4]. Among the different ISF manufacturing process variants, which 
depend on the number of contact points between the forming tool and the sheet, the single point incremental forming (SPIF) is the simplest. In this case, a simple hemispherical end forming tool is used to progressively shape the sheet into a desired arbitrary shape, while the sheet periphery is clamped, as illustrated in Fig. 1. The opposite side of the sheet is simply supported by a backing plate to prevent the bending of the sheet, while the blank holder is employed for clamping and holding the sheet.

Due to the small plastic zone and the incremental nature of the ISF process, the material formability is enhanced in comparison with the one attained in conventional sheet metal forming processes $[5,6]$. Nevertheless, the forming time is much longer than in the conventional processes, such as deep drawing, which is caused by the long travel path of the forming tool. Furthermore, the geometric accuracy of the obtained parts is lower when compared with that in conventional forming processes, which represents an important process limitation [7]. The geometrical error in ISF was defined by Micari et al. [8] as the distance between the ideal profile and the obtained one. In fact, the dimensional accuracy problems arise from the lack of a die to support the metal sheet during the forming process and are amplified due to global/local springback effect [9]. Consequently, several studies have been recently performed in order to improve the final part accuracy and to optimize the forming process [10]. Rauch et al. [11] proposed an approach that adapts and optimizes the tool path during the manufacturing of a part according to process data evaluations (CNC data). The results show that paths generated by commercial computer-aided manufacturing (CAM) software packages are not suitable to carry out ISF applications. The tool path optimization method proposed by Hirt et al. [12] is based on the comparison of the actually formed part geometry (experimentally measured) with the target geometry. The deviation between them is compensated in a second run using an adjusted tool path, which is generated through a correction algorithm based on mirroring the measured points around the target geometry with a scale factor. The finite element method is adopted by Azaouzi and Lebaal [13] to optimize the forming tool path using the response surface method. The

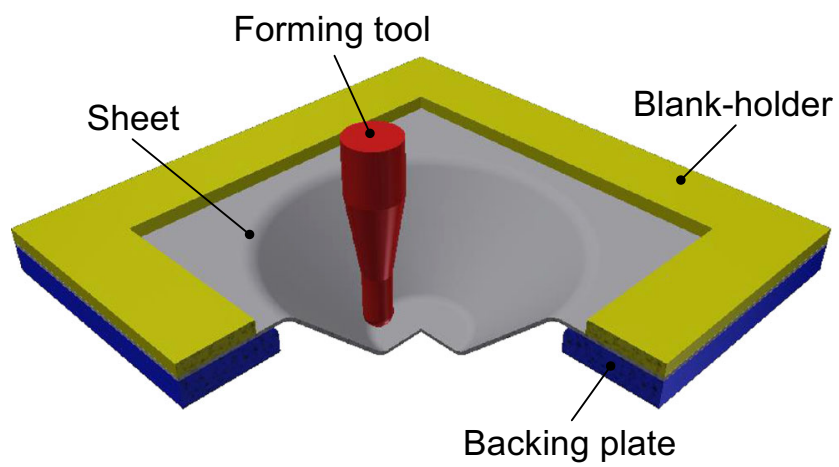

Fig. 1 Illustration of single point incremental forming process principle presented optimization strategy leads to a lower manufacturing time and homogeneous thickness distribution. The laserassisted SPIF process was recently studied by Mohammadi et al. [14] in order to improve the process accuracy. Both finite element analysis and experimental tests are presented for a low-angled conical geometry. A proper laser positioning strategy leads to a significant decrease of the bulge height (pillow effect) and a reduction in radial forming forces. Additionally, the SPIF at elevated temperatures allows enhancement of the formability by lowering the flow stress via dynamic local heating [15].

The prediction of the forming forces generated during the ISF process has been experimentally and numerically studied, which is particularly important when using a robot as a forming platform (typically not a stiff structure). The largest force component in SPIF is developed in the axial direction of the tool. Duflou et al. [16] experimentally investigated the relationship of the forming forces with four process parameters. They concluded that the forming forces increase with the increase of vertical step down size, tool diameter, wall angle and initial sheet thickness. The influence of the contact conditions between the tool and the sheet on features such as surface roughness, forming force and formability was evaluated by Durante et al. [17, 18]. Aerens et al. [19] proposed empirical equations for the prediction of SPIF force (axial, radial and tangential components) based on experimental and finite element results. These equations take into account some of the most important process parameters - sheet thickness, tool diameter, step down and wall angle - which were derived from the results of truncated cones using different materials. An analytical model for tangential force prediction was proposed by $\mathrm{Li}$ et al. [20] for forming of truncated cone shapes. Fiorentino [21] proposed recently a failure criterion based on force monitoring during the forming process. This approach was established by means of the comparison between the ultimate strength of the material and the stresses acting on the material, evaluated from the forming forces. The frictional contact condition between the tool and sheet in SPIF process has been investigated by $\mathrm{Lu}$ et al. [22]. The replacement of the conventional rigid tool by a roller ball tool allows reduction of the friction forces, even when lubricants are not used. Moreover, the surface finish of the formed part is significantly improved, preventing the potential scratch of the sheet surface [23].

The forming limit curve (FLC), which describes the material formability in the minor-major strain plane, is located much upper in the case of ISF than those based on theories of plastic instability. Most of strains are localized close to the major strain axis (plane strain condition), and the FLC can be expressed as a straight line with a negative slope [5]. Jackson and Allwood [24] concluded, by experimental measurements, that the material deformation of ISF is mainly stretching and bending in a plane perpendicular to the tool path and through 
thickness shear in the tool direction. Nevertheless, the role of shear effect on the formability is still not quite clear [25]. The finite element simulation of ISF process has been carried out by several research studies in order to analyse the influence of several process parameters [26] and understand the fundamental deformation mechanism of the sheet metal [27]. However, traditional finite element simulation is significantly timeconsuming due to the moving localized contact zone and long tool path. Although the implicit time integration provides better results in comparison with the explicit analysis, its computational cost is considerably higher. The computational time reported by Smith et al. [28] for the SPIF process of a truncated cone shape is 24 days. In fact, fast and reliable numerical simulations are required to investigate the feasibility of the process in an industrial context, namely, the prediction of failure occurrence [29]. Bambach [30] proposed combining remeshing and subcycling methods to reduce the computational effort, achieving savings in CPU time of up to $80 \%$ for a cone shape part. A simplified finite element model was developed by Ben Ayed [31], where the management of the contact between the tool and the sheet is simplified replacing the tool action by imposed displacements.

The purpose of this paper is to improve the understanding of the SPIF process by means of a comprehensive numerical study based on the finite element method. The proposed numerical model is firstly validated with experimental results, namely, the forming force evolution, the thickness profile and the strain distribution of a simple truncated cone (AA7075-O aluminium alloy), proposed as benchmark in the Numisheet 2014 conference [32]. Afterwards, the state of strain and stress is evaluated in the vicinity of the contact area, where the plastic deformation increases by means of the forming tool action. The modelling of the metallic sheet using solid finite elements allows an accurate evaluation of the residual stresses generated by the cyclic loading created by the tool path. Besides, the material deformation mechanisms are studied in detail. The experimental setup of the SPIF manufacturing of a truncated cone is described in Sect. 2, while the proposed finite element model is presented in Sect. 3. The comparison between numerical and experimental results is carried out in Sect. 4, showing the state of stress and strain field in the formed part. The main conclusions of this study are discussed in Sect. 5 .

\section{Experimental setup}

The single point incremental forming of a truncated cone is the example considered in the present study (Fig. 2), which was recently proposed as benchmark in the Numisheet 2014 conference [32]. The AA7075-O aluminium alloy is the material selected for the experimental tests, which is typically used in aircraft structures due to its high strength. The geometry of the

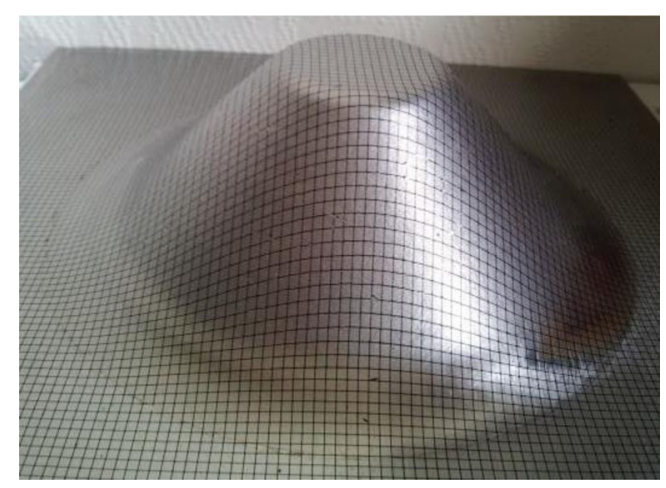

Fig. 2 Truncated cone shape with inclination angle of $45^{\circ}$ produced using SPIF process [32]

sheet is square with edge length of $222 \mathrm{~mm}$ and initial thickness of $1.63 \mathrm{~mm}$. The clamping of the blank into the backing plate is performed using the blank holder, which constraints the blank movement inside a region of $32 \mathrm{~mm}$ wide to the edge (see Fig. 1). The backing plate presents a hole with $140 \mathrm{~mm}$ of open diameter and $4 \mathrm{~mm}$ of curvature radius, while the hemispherical forming tool has a diameter of $12.66 \mathrm{~mm}$. The SPIF process was carried out using a three-axis CNC milling machine, adopting a tool path designed by CAM software.

The tool path consists of a series of circular contours in the clockwise direction followed by a vertical downwards movement of $\Delta z=0.5 \mathrm{~mm}$ between each neighbouring contour, as shown in Fig. 3. The radius of the circular path is reduced at each vertical movement using a step over size $\Delta x=0.5 \mathrm{~mm}$, where the major diameter is $124 \mathrm{~mm}$ and the angle between the cone wall and the horizontal plane is $45^{\circ}$. The average velocity of the forming tool (feed rate) is $25 \mathrm{~mm} / \mathrm{s}$, leading to a total forming time of about $1330 \mathrm{~s}(22 \mathrm{~min})$. The contact between the forming tool and the metallic sheet is lubricated with sufficient oil in order to reduce friction and avoid excessive wear of the tool surface. The non-contact surface of the aluminium sheet is electrochemically etched with a regular rectangular grid pattern in order to measure the principal

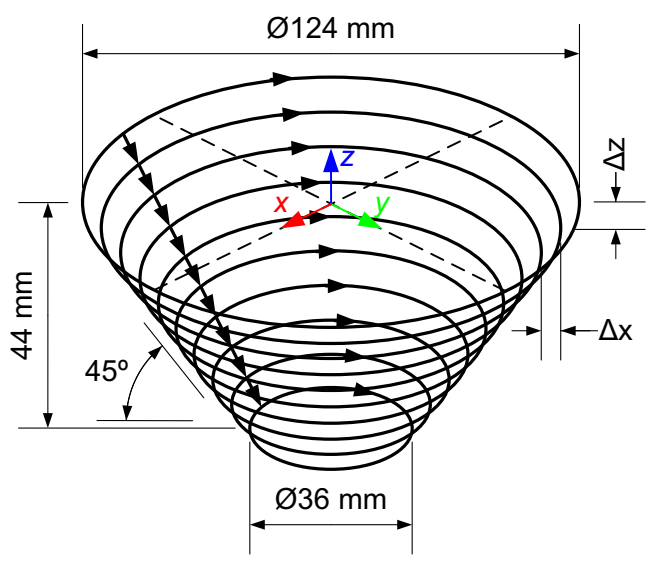

Fig. 3 Description of the z-level tool path adopted in the truncated cone forming with identification of the vertical step down size $(\Delta z)$ and step over size $(\Delta x)$ 
strains after forming. The axial component of the forming force acting on the forming tool is measured continuously during the process using a table-type force dynamometer. All experimental results presented in this study were provided by the benchmark committee [32].

\section{Finite element modelling}

In the present study, the numerical simulation of the SPIF process is performed with the in-house static implicit finite element code DD3IMP [33], which has been specifically developed to simulate sheet metal forming processes [34]. The evolution of the deformation process is described by an updated Lagrangian scheme. The non-linear system of equations resulting from the static equilibrium of the model considered is solved iteratively using the Newton-Raphson method. In order to improve the convergence of the iterative procedure, an explicit approach is used to calculate the trial solution, which enables the adjustment of the increment size using a generalization of the $r_{\min }$ strategy. The frictional contact problem is regularized by the augmented Lagrangian method [35], leading to a mixed system of equations involving both nodal displacements and contact forces as unknowns. In order to improve computational performance, some highperformance computing techniques have been incorporated to take advantage of multi-core processors, namely, OpenMP directives in the most time-consuming branches of the code [36]. The numerical simulation is carried on a computer machine equipped with an Intel ${ }^{\mathbb{E}}$ Core $^{\mathrm{TM}}$ i7-2600 K Quad-Core processor $(3.4 \mathrm{GHz})$ and the Windows 7 Professional (64-bit platform) operating system.

Both the forming tool and the backing plate are considered as rigid bodies, while their outer surfaces are modelled with Nagata patches [37, 38]. The discretization of the rigid tools involved in the numerical simulation is presented in Fig. 4.

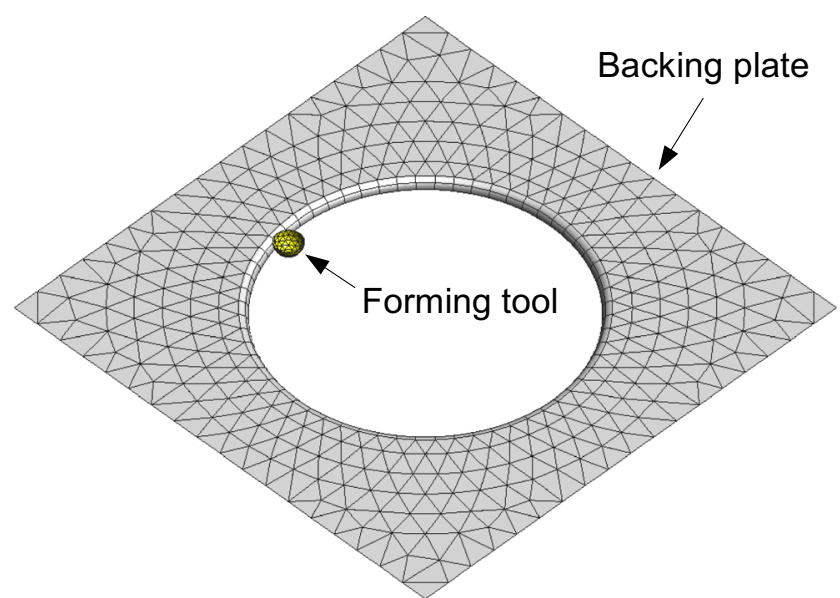

Fig. 4 Discretization of the forming tool and the backing plate using Nagata patches
The surface of the forming tool is described by 100 triangular Nagata patches, while the backing plate is described using 612 triangular patches and 120 quadrilateral Nagata patches. The friction arising between the blank and the forming tool is modelled through the classical Coulomb's law, using a small value of friction coefficient $\mu=0.01$, as suggested in the benchmark specifications [32]. The movement of the tool follows the experimental path (see Fig. 3), which was generated by means of the CAM software designed for milling. The tool path comprises a series of complete circular contours $\left(360^{\circ}\right)$ followed by a downwards increment of $0.5 \mathrm{~mm}$ after each completed contour. Since the contact zone between the tool and the sheet is small and is continually changing with the tool movement, each complete circular contour is discretized into 900 straight paths, leading to angular increments of $0.4^{\circ}$ for the tool in relation to the truncated cone axis.

Considering that the blank is completely clamped during the forming process, the blank holder presenting a $158 \times$ $158 \mathrm{~mm}$ square hole (see Fig. 1) is not modelled. Hence, the four edges of the square blank located in the transition to the blank holder are totally clamped in all directions to represent the clamping system. The blank is discretized with hexahedral finite elements, associated with a selective reduced integration scheme [39], allowing the accurate evaluation of the contact forces and the through-thickness shear and bending effects. The square blank geometry located inside the blank holder is divided in two regions, as shown in Fig. 5. The region which will be contacting with the tool (circular ring) is discretized with a radial mesh comprising 360 finite elements in the circumferential direction (size between 0.3 to $1.2 \mathrm{~mm}$ ) and 80 elements in the radial direction (size between 0.4 to $1.3 \mathrm{~mm}$ ). The region of the blank situated outer to the circular ring is discretized with a relatively coarse unstructured mesh, while the central circle is composed of transition finite elements, as illustrated in Fig. 5. The discretization of the blank comprises

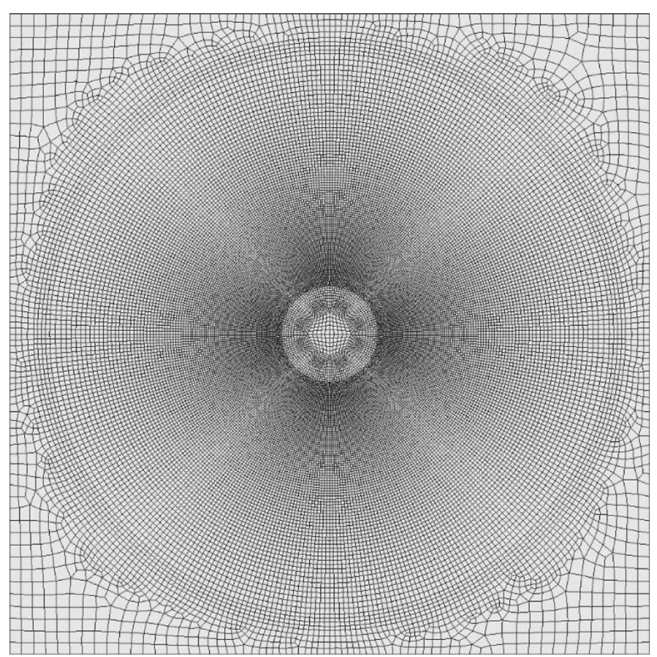

Fig. 5 Finite element mesh of the blank inside the blank holder (edge length of $158 \mathrm{~mm}$ ) 
two layers of finite elements through the thickness, which are sufficient to capture the shear deformation on the thickness [7], leading to a total of 71,522 finite elements.

\subsection{Constitutive material modelling}

The mechanical behaviour of the AA7075-O aluminium alloy is assumed to be elastic-plastic. Thermal and strain rate effects are not included in the present model. The elastic behaviour is considered isotropic and constant, which is described by Hooke's law with Young's modulus of $72 \mathrm{GPa}$ and Poisson ratio of 0.33 [32]. The characterization of the plastic behaviour involves the specification of a hardening law, a yield function, and in this case, an associated flow rule by which the subsequent plastic deformations can be calculated. The isotropic work hardening behaviour is modelled by the Swift law:

$$
Y=K\left(\varepsilon_{0}+\bar{\varepsilon}^{\mathrm{p}}\right)^{n} \quad \text { with } \quad \varepsilon_{0}=\left(\frac{\sigma_{0}}{K}\right)^{1 / n},
$$

where $Y$ is the flow stress and $\bar{\varepsilon}^{\mathrm{p}}$ denotes the equivalent plastic strain. The initial yield stress $\sigma_{0}$, the initial yield strain $\varepsilon_{0}$, the hardening coefficient $K$ and the hardening exponent $n$ are material parameters. The orthotropic behaviour of the aluminium sheet, resulting from the rolling process, is described by the Yld91 yield criterion proposed by Barlat et al. [40], which is an extension to orthotropy of the Hosford isotropic yield criterion [41]. It can be expressed by the following nonquadratic function:

$$
\left|S_{1}-S_{2}\right|^{m}+\left|S_{2}-S_{3}\right|^{m}+\left|S_{3}-S_{1}\right|^{m}=2 \bar{\sigma}^{m},
$$

where $S_{1}, S_{2}$ and $S_{3}$ are the principal values of the isotropic stress deviator tensor, which is obtained from the linear transformation applied to the Cauchy stress tensor $\mathbf{S}=\mathbf{L}: \boldsymbol{\sigma}$. The exponent $m$ is connected to the material crystallographic structure, i.e. $m=6$ for BCC and $m=8$ for FCC metals, which provides the shape of the yield surface. The six anisotropy coefficients are contained in the linear transformation matrix L [40].

The material parameters for the AA7075-O aluminium alloy have been identified by fitting the constitutive model to the experimental results of conventional uniaxial tensile tests, provided by the benchmark committee [32]. The obtained material coefficients for the Swift isotropic work hardening law and for the Yld91 yield criterion are presented in Table 1. The coefficients for the Swift law are identified by fitting the experimental stress-strain curve measured at the rolling direction (RD). The yield surface shape described by the Yld91 model is calibrated using 14 experimental points, namely seven $r$-values and seven yield stresses, both measured at various directions with respect to the RD (increments of $15^{\circ}$ from $\mathrm{RD}$ ). The anisotropic characteristics of AA7075-O aluminium alloy are given in Fig. 6, comparing experimental and numerical distributions for the yield stresses and $r$-values. The values predicted by the numerical model (Yld91 yield criterion) are in good agreement with the experimental ones, particularly the $r$-value. The uniaxial true stress-true strain curves obtained with the numerical model at $0^{\circ}, 45^{\circ}$ and $90^{\circ}$ with respect to the RD are presented in Fig. 7. These numerical results are in accordance with the experimental curves of the uniaxial tensile tests performed by Li et al. [20] for the same aluminium alloy and sheet thicknesses.

\section{Results and discussion}

\subsection{Forming forces}

The influence of four process parameters (sheet thickness, vertical step down size, tool diameter and wall angle) on the tool force was firstly studied by Filice et al. [42] for diverse truncated cones. They show, through experimental tests, that the tool force increases with increase of all these parameters, as expected. The comparison between experimental and numerical forming tool force evolution is presented in Fig. 8, for the truncated cone with wall inclination angle of $45^{\circ}$. Only the vertical component of the forming force is measured experimentally since it presents the higher amplitude. In the current geometry, the sequence of circular tool paths leads to sinusoidal evolutions for both horizontal force components $\left(F_{\mathrm{x}}\right.$ and $F_{\mathrm{y}}$ ) measured in the global Cartesian coordinate system (see Fig. 3). Thus, the horizontal component of the tool force $F_{\mathrm{x}, \mathrm{y}}$ is decomposed into tangential and radial directions, as schematically illustrated in Fig. 9. This allows evaluation of both the tangential and the radial force amplitude in function of the process time (about $22 \mathrm{~min}$ ), as shown in Fig. 8 for the numerical prediction.

The amplitude of the tangential force $\left(F_{\mathrm{t}}\right)$ predicted by the numerical model increases gradually from the beginning of the forming process to attaining the steady state. During this period, bending is the most relevant deformation mechanism [16]. The radial component of the force only reaches the
Table 1 Constitutive law parameters for the AA7075-O

\begin{tabular}{|c|c|c|c|c|c|c|c|c|c|}
\hline \multicolumn{3}{|c|}{ Swift hardening law } & \multicolumn{7}{|c|}{ Yld91 yield criterion } \\
\hline$K(M P a)$ & $n$ & $\varepsilon_{0}$ & $c_{1}$ & $c_{2}$ & $c_{3}$ & $c_{4}$ & $c_{5}$ & $c_{6}$ & $m$ \\
\hline 343.3 & 0.184 & 0.0015 & 1.098 & 1.128 & 0.986 & 1.000 & 1.000 & 0.978 & 8 \\
\hline
\end{tabular}
aluminium alloy 


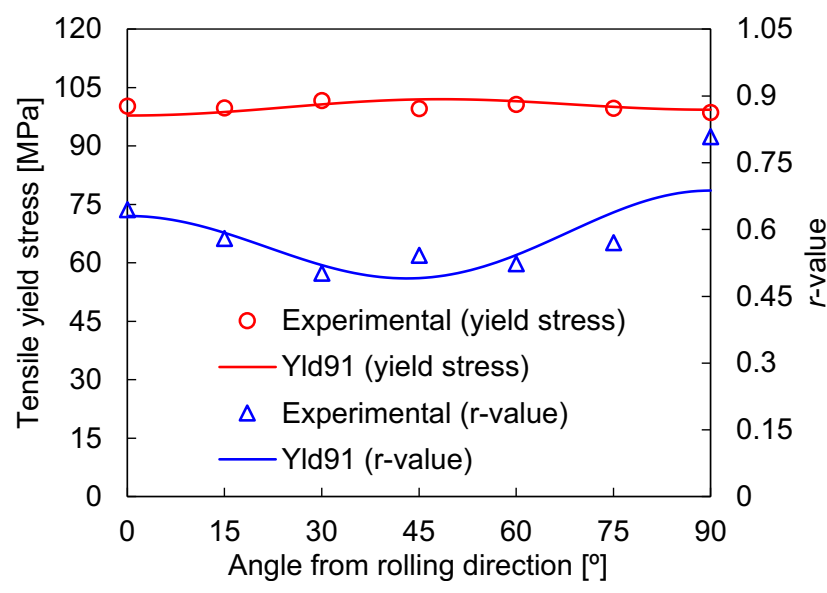

Fig. 6 Tensile yield stress and $r$ value in the sheet's plane for the AA7075-O aluminium alloy considering the Yld91 yield criterion

steady state when the contact area of the forming tool is fully evolved, i.e. the slope angle is $45^{\circ}$, which occurs for approximately $600 \mathrm{~s}$ of process time. An identical trend is obtained for the vertical (axial) force component, which is in agreement with the experimental result. Nevertheless, the experimental force is slightly overestimated by the finite element model (see Fig. 8), mainly at the beginning. This difference can result from a small amount of sliding between the metal sheet and the clamping frame, which is not considered in the numerical model. Besides, the force decreases when the kinematic hardening is taken into account, as reported by Flores et al. [43]. After reaching the steady state, the forming force remains approximately constant due to the combined effects of strain hardening (force increasing) and thinning (force reduction). Assuming that the tensile strength of this aluminium alloy is $198 \mathrm{MPa}$ [44], the axial force value predicted through the empirical equation proposed by Aerens et al. [19] is $1816 \mathrm{~N}$, which is analogous to the steady state value provided by the finite element simulation, as shown in Fig. 8. The depth increment between consecutive contours produces a pulse in the

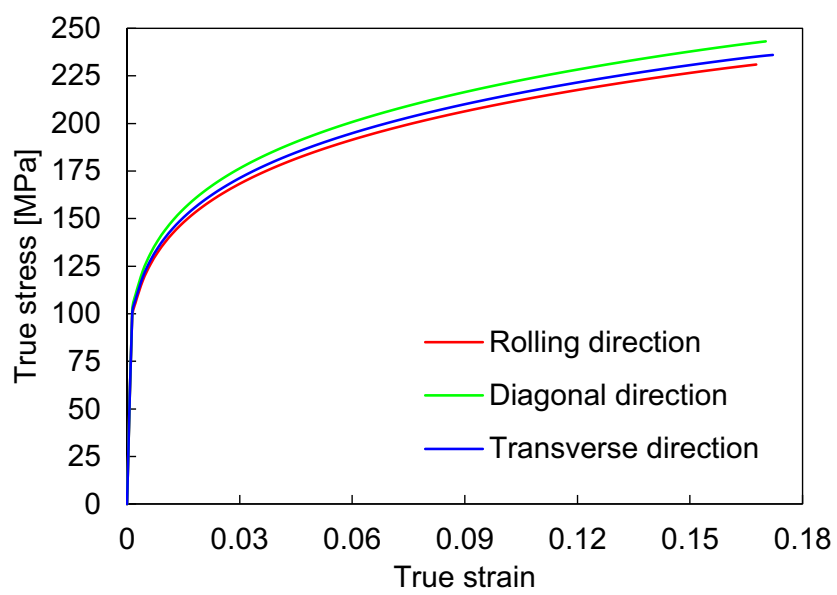

Fig. 7 True stress-true strain curves at different directions for the AA7075-O aluminium alloy modelled by the Swift law and Yld91 yield criterion experimental force evolution, where the $F_{\mathrm{z}}$ component drops when the tool completes a circular path and then reaches its peak value at the step down increment [19]. The spikes in the numerical tool force evolution were removed for visualization purposes.

\subsection{Final geometry}

The main drawback of the tooling simplicity in the SPIF process is the lack of geometrical accuracy achieved in the formed product [8]. The comparison between numerical and experimental measurements of the truncated cone is presented in Fig. 10 for two orthogonal cutting planes (rolling and transverse directions). In order to quantify the geometrical error with respect to the theoretical profile, the CAD geometry of the truncated cone is also presented in Fig. 10. The simulation results are in good agreement with the experimental ones. Indeed, the finite element model predicts accurately the sheet bending near the major diameter of the cone and the pillow effect (concave curvature) on the minor base, which are both overlooked through the theoretical (CAD) geometry. The experimental wall inclination is in good agreement with the CAD geometry; nevertheless, the diameter of the cone is overestimated both by the CAD geometry and by the numerical simulation. Since the AA7075-O aluminium alloy presents only a slightly in-plane plastic anisotropy (see Fig. 6), the profile section of the truncated cone after unloading is identical in the rolling and transverse directions, as shown in Fig. 10.

The undesirable springback effect is the main source of geometric inaccuracy, which was defined by Jeswiet et al. [1] as being of local and global type. Thus, in order to evaluate the springback that occurs during the forming operation, the displacement history of six Gauss points located in the cone wall is analysed between two instants. The location of the selected Gauss points is schematically presented in Fig. 11 for the two instants under analysis, corresponding to 12 circular contours ( $6 \mathrm{~mm}$ of vertical tool displacement). Three Gauss points are located near the upper surface (denoted as GPx_U) and the others near the lower surface (denoted as GPx_L). The initial distance between two adjacent Gauss points in the sheet plane is approximately $2.2 \mathrm{~mm}$.

The local springback occurring during the incremental forming can be analysed through the vertical displacement of the sheet [45], namely, its local upwards movement. The evolution of the z-coordinate in the selected six Gauss points is presented in Fig. 12, for a forming time of $150 \mathrm{~s} \mathrm{(12} \mathrm{circular}$ contours). The vertical movement of the Gauss points located in the lower surface is similar to the one predicted for the upper surface due to the rigid body motion. The movement pattern is identical for all circular tool paths, presenting a downwards movement when the tool comes close to the Gauss point (half circular contour) and an upwards movement 
Fig. 8 Evolution of the forming tool force measured in three orthogonal directions (vertical, radial and tangential) predicted by finite element simulation and observed experimentally (vertical component)

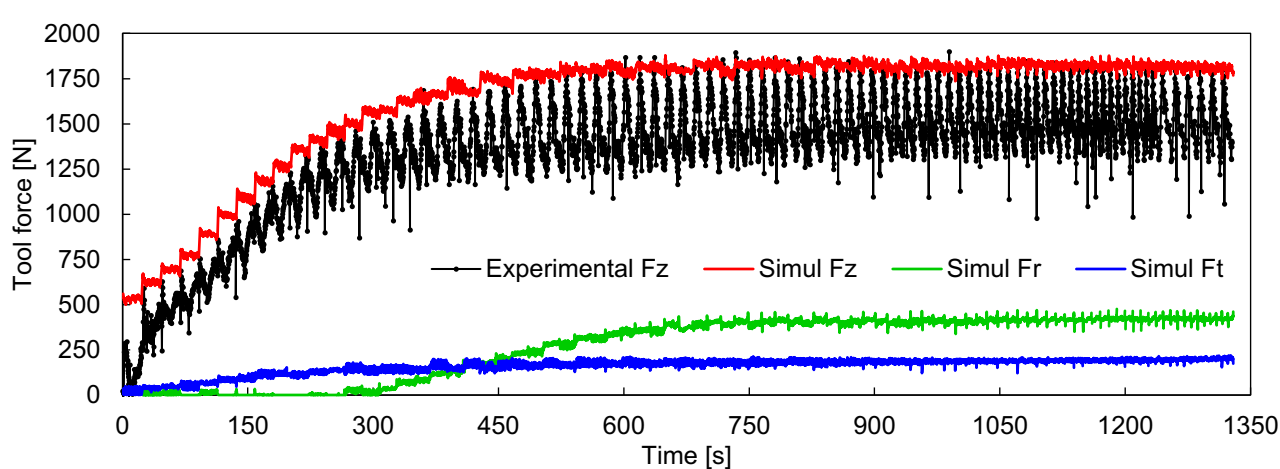

when the tool progresses away from the Gauss point (half circular contour). The local springback is highlighted by the continuous movement of the sheet during the forming operation, as shown in Fig. 12. This occurs mainly in the minor base of the cone due to the lack of a backing plate to support the sheet. The pillow effect in the minor base of the cone can be assessed using the vertical coordinate of the Gauss points. In fact, when the forming tool passes exactly over the Gauss point GP1_U (corresponding to a forming time of $994 \mathrm{~s}$ and depth of $26 \mathrm{~mm}$ ), its depth is higher than the depth of the Gauss points GP2_U and GP3_U (see Fig. 12), which are close to the cone centre (see Fig. 11). Therefore, the magnitude of $\mathrm{z}$-coordinate evaluated in the radial direction decreases from the corner of the cone to the centreline. The Gauss point GP1_U switches from the minor cone base to the wall at approximately $1050 \mathrm{~s}$ of forming time, where its vertical movement is substantially lower, as shown in Fig. 12.
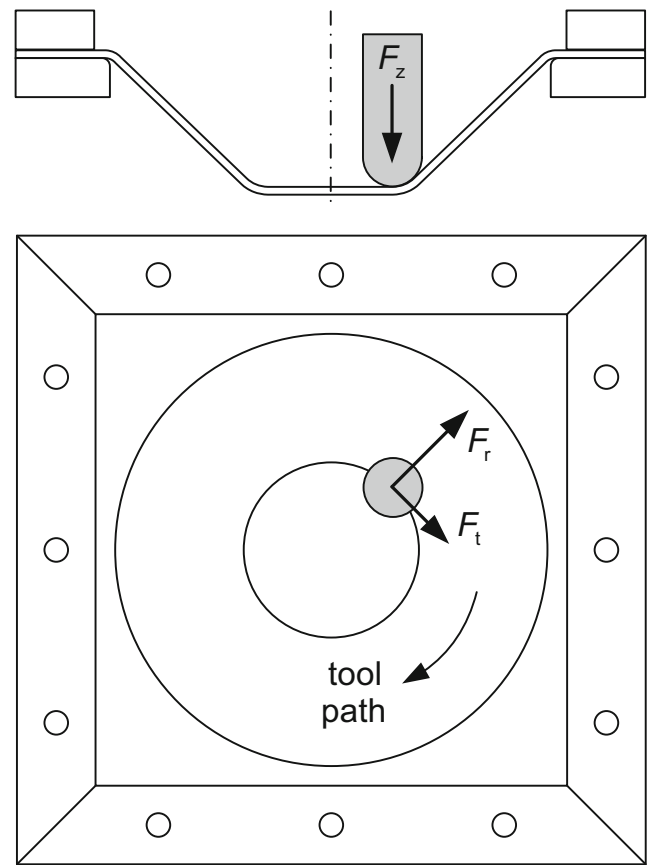

Fig. 9 Decomposition of the forming tool force into vertical $\left(F_{\mathrm{z}}\right)$, radial $\left(F_{\mathrm{r}}\right)$ and tangential $\left(F_{\mathrm{t}}\right)$ components for the truncated cone forming

\subsection{Twisting angle}

The rotation of the sheet with respect to the clamped edge in incremental forming is called twisting [46]. This phenomenon results from the tangential forces exerted by the forming tool on the sheet, arising predominantly when a unidirectional tool path is adopted [47]. The predicted twist in the truncated cone during the forming process is presented in Fig. 13, using the distortion of the radial line, initially aligned with the rolling direction. The deformed profile is presented for three different process instants, where the clockwise deformation is a consequence of the clockwise tool path (see Fig. 3).

The deformed radial line can be divided in three distinct sectors, defined by straight lines, corresponding to the (i) cone base, (ii) inclined cone wall and (iii) flange. The twist arising in the base of the cone results from the action of the forming tool in the wall (radial distance between 20 and $60 \mathrm{~mm}$ ), while the cone flange does not contain twist phenomena due to the clamping conditions. Since the deformed profile associated to

(a)

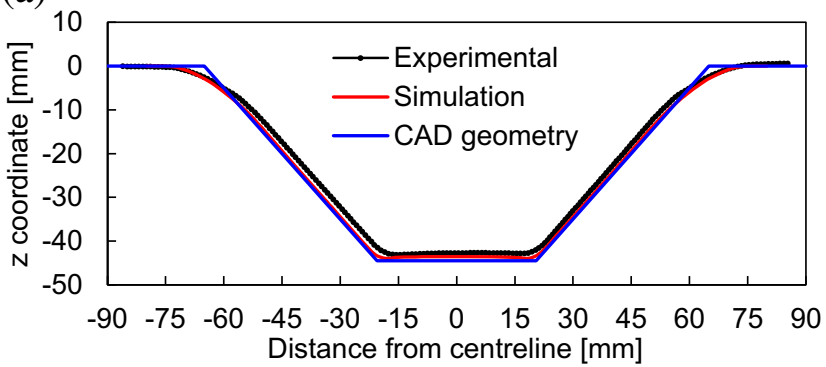

(b)

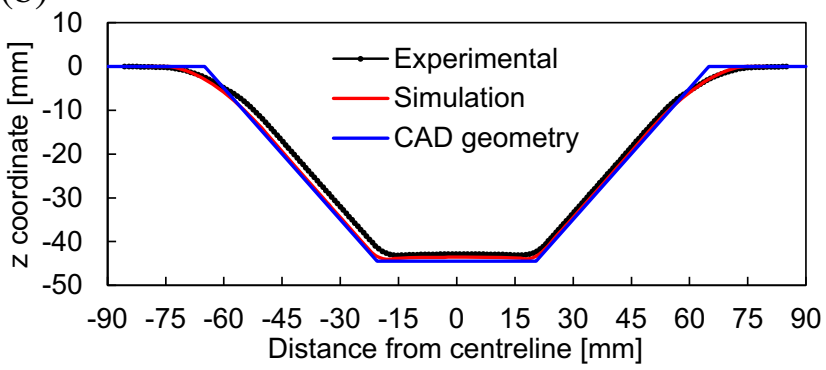

Fig. 10 Comparison between ideal (CAD geometry) and real profile (experimental and simulation) after unloading in the cross section: a rolling direction; $\mathbf{b}$ transverse direction 


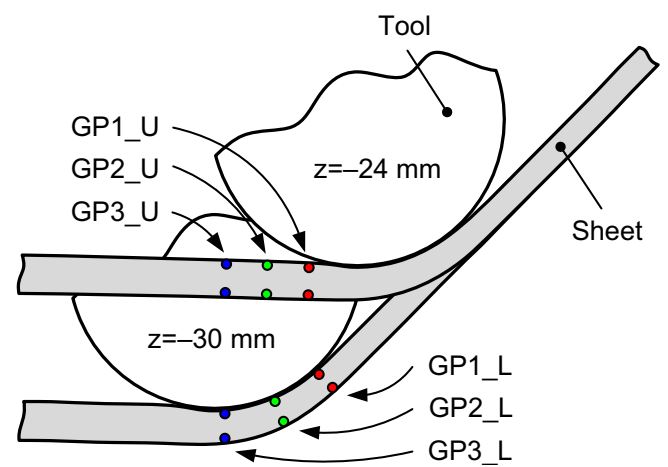

Fig. 11 Location of six Gauss points used to evaluate the local springback and the stress state in the sheet when the tool passes over it

the cone wall is nearly a straight line (Fig. 13), the twist angle is approximately uniform over the entire height of the truncated cone. Additionally, since the profile curves are coincident in the common wall section, the twist angle value is constant during the entire forming process. On the other hand, the twist angle in the cone base presents an exponential evolution with the process time, as shown in Fig. 14. This is due to the inevitable diameter reduction of the cone bottom during the process progress, while the wall twist angle is kept constant. In fact, the twist angle in the cone bottom is about $0.5^{\circ}$ for $20 \mathrm{~mm}$ of tool depth and after forming (tool depth of $44 \mathrm{~mm}$ ) is $2.5^{\circ}$.

\subsection{Sheet thickness}

The thickness distribution in two cross sections (rolling and transverse directions) of the truncated cone geometry is presented in Fig. 15, comparing experimental and numerical results. Additionally, the final thickness of the truncated cone predicted by the sine law [48] is also presented, which is based in the assumption of the incompressibility condition (constant volume). According to the sine law, the final wall thickness

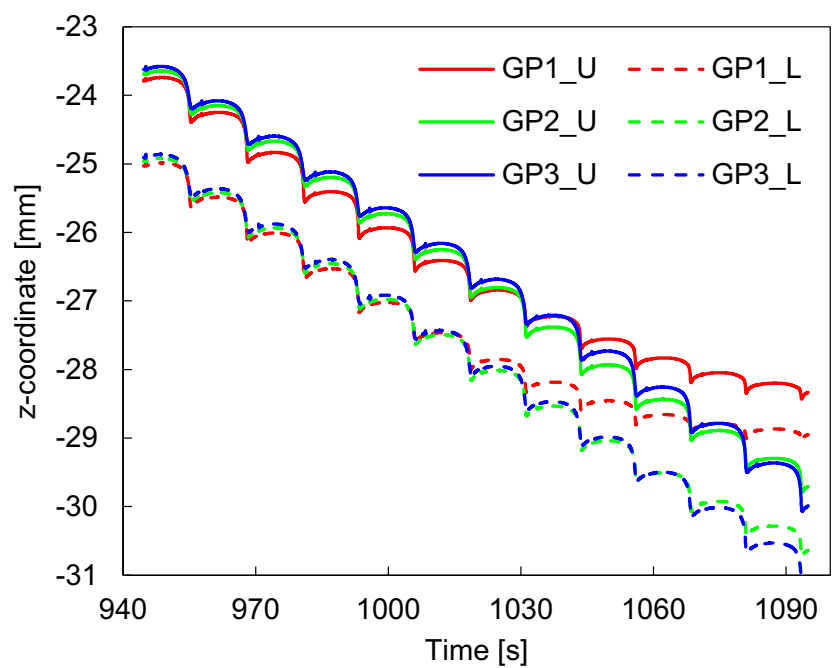

Fig. 12 Numerical evolution of the z-coordinate measured in six different Gauss points of the sheet

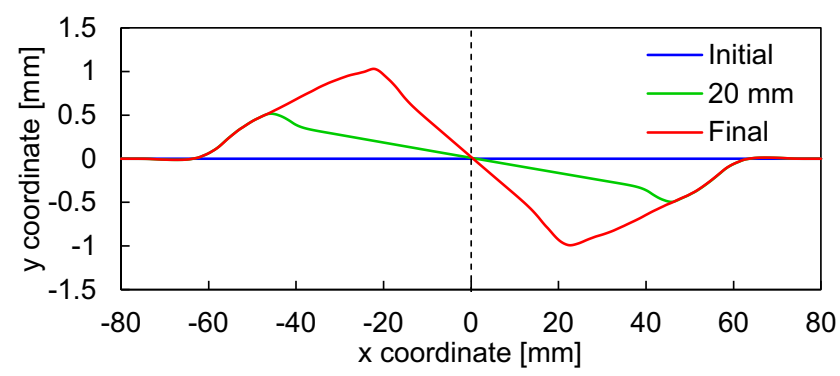

Fig. 13 Twist in the truncated cone predicted by the numerical model for three different instants

decreases with the increase of the wall angle, which is observed experimentally. Nevertheless, this analytical model provides a poor prediction of the thickness in the bending region (near the major diameter of the cone). Furthermore, the minimum value of thickness (located in the cone wall) is overestimated by the sine law, as shown in Fig. 15. On the other hand, the numerical results are in good agreement with the experimental results for the entire sector. The predicted thinning band in the thickness from 45 to $50 \mathrm{~mm}$, along the radial direction, was observed experimentally by Young and Jeswiet [49] for the same geometry. Signs of localized necking, similar to what appears in a uniaxial tensile test, were observed by them in this zone. The effect of the thinning band on the sheet formability was posteriorly investigated by Hussain et al. [50]. They concluded that the occurrence of thinning bands on the parts is not obligatory for all materials. The difference arising between the two cross sections studied is negligible due to the small plastic anisotropy in-plane (see Fig. 6). Thus, a rough approximation of the thickness distribution can be quickly obtained using the sine law, while the finite element simulation provides an accurate prediction of the thickness at reasonable computational cost.

The thickness distribution in the truncated cone after forming is presented in Fig. 16. Although the tool path adopted (see Fig. 3) and the boundary conditions applied, the thickness distribution is approximately axisymmetric. The final thickness both in the flange and in the bottom of the cone is identical to the initial thickness (slight sheet thinning). The downwards movement of the forming tool between consecutive circular contours (always in the same angular

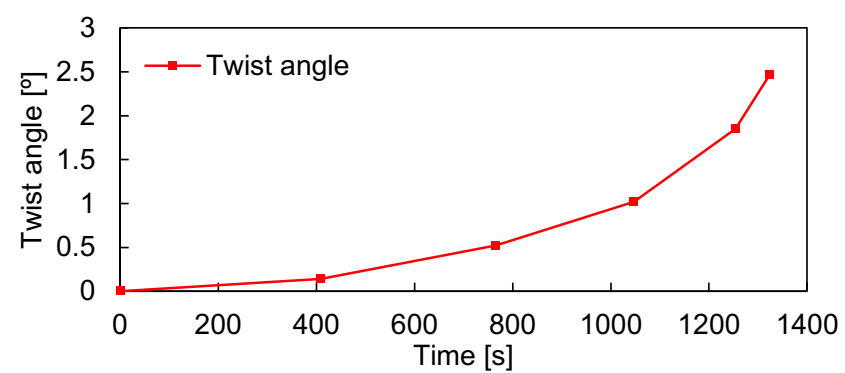

Fig. 14 Evolution of the twist angle in the base of the truncated cone during the single point incremental forming process 


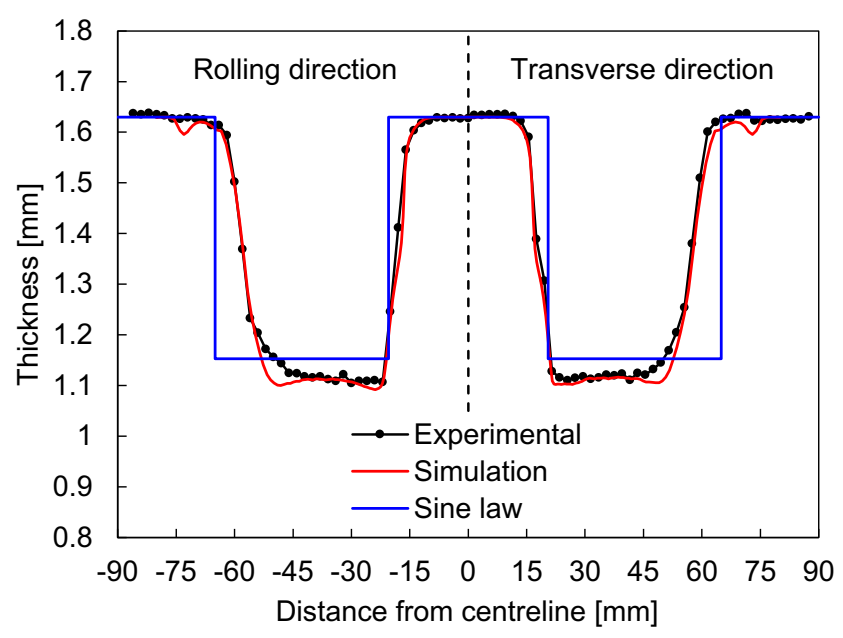

Fig. 15 Comparison between experimental and predicted thickness distribution in two cross sections

position) produces a scarring in the cone wall [51]. Accordingly, the final thickness along a line down the wall cone is slightly altered in comparison with other cross sections, as illustrated in Fig. 16. The thinning is marginally lower in this zone, specifically in the position located immediately before the angular position where the tool realizes its vertical increment. A spiral tool path allows obtaining a truncated cone with no surface marks and approximately axisymmetric thickness distribution, since the downwards increment is continuous over the complete contour [52].

\subsection{Strain analysis}

The comparison between experimental and predicted plastic strain distribution in the non-contact surface of the truncated cone is presented in Fig. 17 for two orthogonal cross sections (rolling and transverse directions). The finite element results are in good agreement with the experimental measurements, where the plastic strain distribution is approximately axisymmetric. Moreover, the plastic strain is nearly zero in the bottom of the cone (around $30 \mathrm{~mm}$ of diameter), as well as in the flange. Since the hoop strain is negligible in comparison with

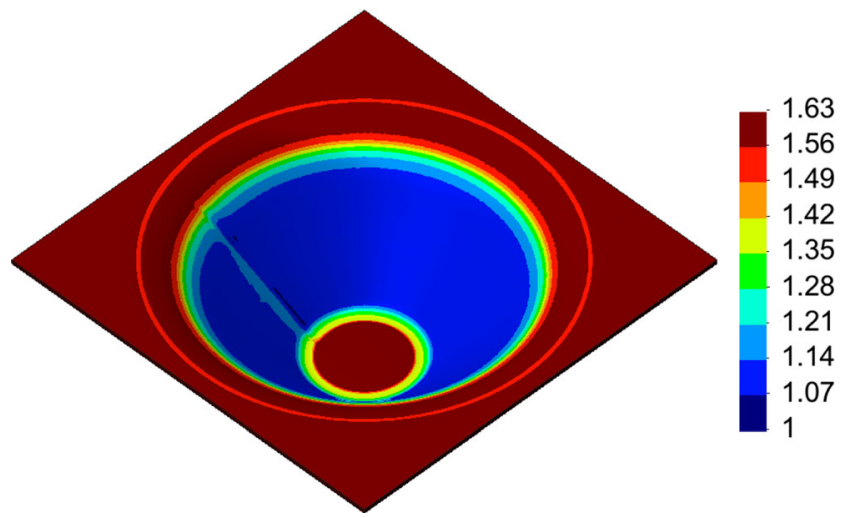

Fig. 16 Thickness distribution in the truncated cone after forming

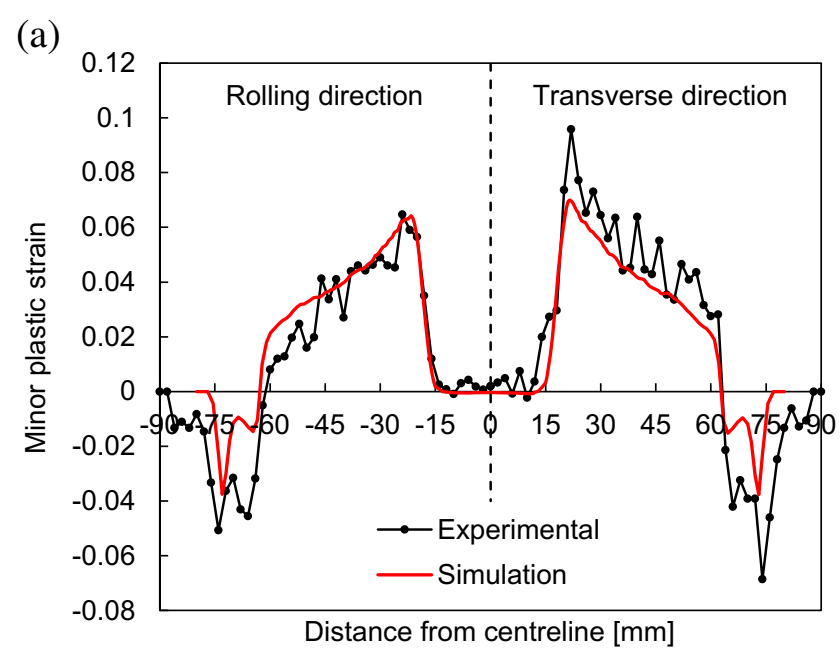

(b)

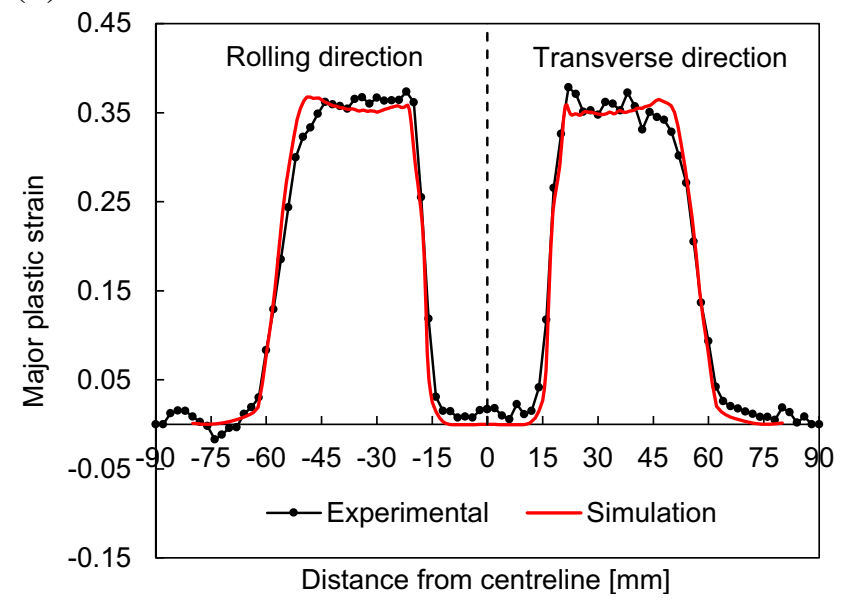

Fig. 17 Comparison between experimental and predicted plastic strain distribution evaluated in the non-contact surface: a minor plastic strain; $\mathbf{b}$ major plastic strain

the meridional strain [28], the minor plastic strain (Fig. 17a) is considerably lower than the major plastic strain (Fig. 17b) in the forming area. Therefore, the (negative) thickness strain is mainly dictated by the meridional strain, leading to a distribution of the major plastic strain analogous to the final thickness distribution (see Fig. 15). In fact, the major strain is approximately uniform in the cone wall, justifying to the adoption of the sine law for the final thickness prediction [53]. The minor plastic strain is negative in the bending region, located near the major diameter of the cone, while the forming region presents positive values of minor strain.

The minor-major strain distribution in the exterior surface of the cone is presented in Fig. 18 for the cross section aligned with the rolling direction. The numerical results are in good agreement with the experimental ones, as previously observed for each strain component separately (see Fig. 17). The deformation mode conditions in the truncated cone are nearly under plane strain [54] because the material mainly deforms along the meridional direction. Flores et al. [43] tracked the strain 


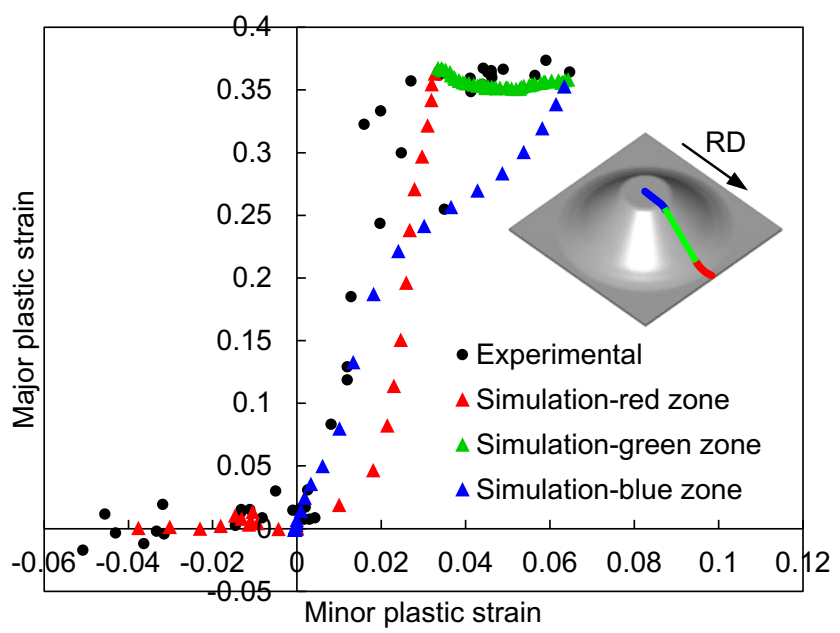

Fig. 18 Comparison between experimental and predicted minor-major strain distribution in the cross section aligned with the rolling direction (non-contact surface)

history of one material point when forming a conical part and found that the circumferential strain is near zero. Nevertheless, the strain distribution presents a slight deviation towards biaxial stretching conditions, which occurs in the transition zone between the inclined wall and the bottom corner radius of the sheet (see Fig. 18). In fact, the material failure arises in this zone, and the opening mode of the cracks results from the meridional tensile stresses (mode I of fracture mechanics) [29]. The deformation achieved in the SPIF process exceeds the forming limits of conventional sheet forming due to the presence of hydrostatic pressure, which is produced by the elastic deformation of the area neighbouring the local contact area [3]. Since the FLC in SPIF can be expressed as a straight line with a negative slope in the minor-major strain plane [5], according to Fig. 18 the fracture will arise in the corner of the cone, which is in accordance with experimental observations for this geometry [50].

The distribution of the equivalent plastic strain predicted by the finite element model is presented in Fig. 19 for both internal and external surfaces of the cone. Due to the contact between forming tool and sheet, the maximum values of plastic strain arise in the interior surface of the cone. Indeed, the value of equivalent plastic strain is approximately $15 \%$ lower in the

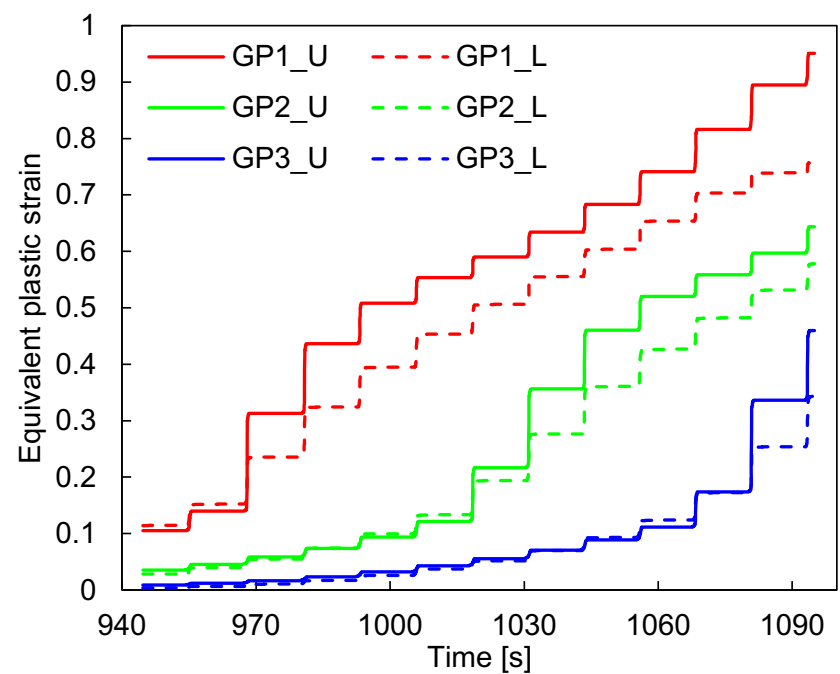

Fig. 20 Evolution of the equivalent plastic strain measured in six different Gauss points of the sheet

exterior surface, as shown in Fig. 19. Moreover, the effect of the plastic anisotropy of the aluminium alloy is highlighted in the exterior surface of the cone through the equivalent plastic strain distribution.

The evolution of the equivalent plastic strain as function of the process time is presented in Fig. 20 for the six Gauss points indicated in Fig. 11. The analysed time is restricted to $150 \mathrm{~s}$, corresponding to 12 circular contours of the forming tool. The localized nature of the plastic deformation in SPIF dictates that the plastic strain increases stepwise under the action of the tool, as illustrated in Fig. 20. In fact, the increment of plastic strain is negligible when the tool is far away from the Gauss point. However, the plastic deformation also occurs in the cone wall neighbouring the contact area, as shown by means of the plastic strain increment arising in Gauss points GP1 and GP2 when the tool passes just over the Gauss point GP3 (see forming time of $1094 \mathrm{~s}$ in Fig. 20). The same trend was experimentally observed by Eyckens et al. [27] using digital image correlation to measure the outer surface strain components. The abrupt increase in the plastic strain occurs at the same instant for all points because they are located in the same cross section (aligned with the rolling direction). The magnitude of the steps is directly related with the vertical step
Fig. 19 Equivalent plastic strain distribution after forming a interior cone surface and $\mathbf{b}$ exterior cone surface

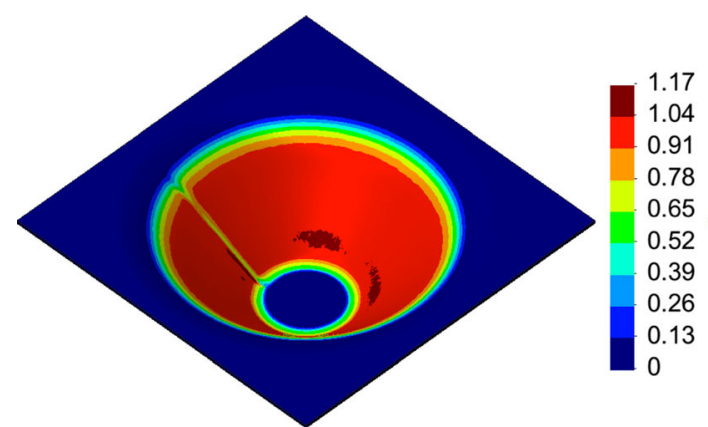

(a)

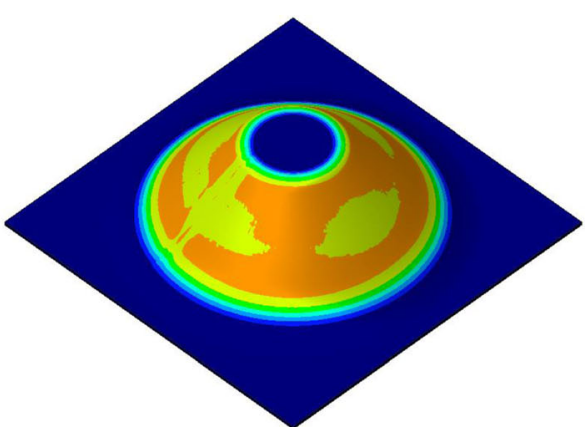

(b) 
down size $\Delta z$ used in the tool path (Fig. 3) and the radial proximity of the tool.

\subsection{Stress analysis}

The analysis of the stress field in the formed part is considerably more difficult than the study of strains. In fact, the former can be evaluated experimentally [27], while the stress state can only be estimated by means of analytical approaches [29] or using the finite element analysis. In the present study, the adoption of solid finite elements to model the complete forming process allows to study accurately the 3D stress distribution under the forming tool. The evolution of the normal stress components expressed in a local coordinate system $\left(\sigma_{11}\right.$, meridional stress; $\sigma_{22}$, circumferential stress; and $\sigma_{33}$, thickness stress) is presented in Fig. 21 for the Gauss points GP1_U
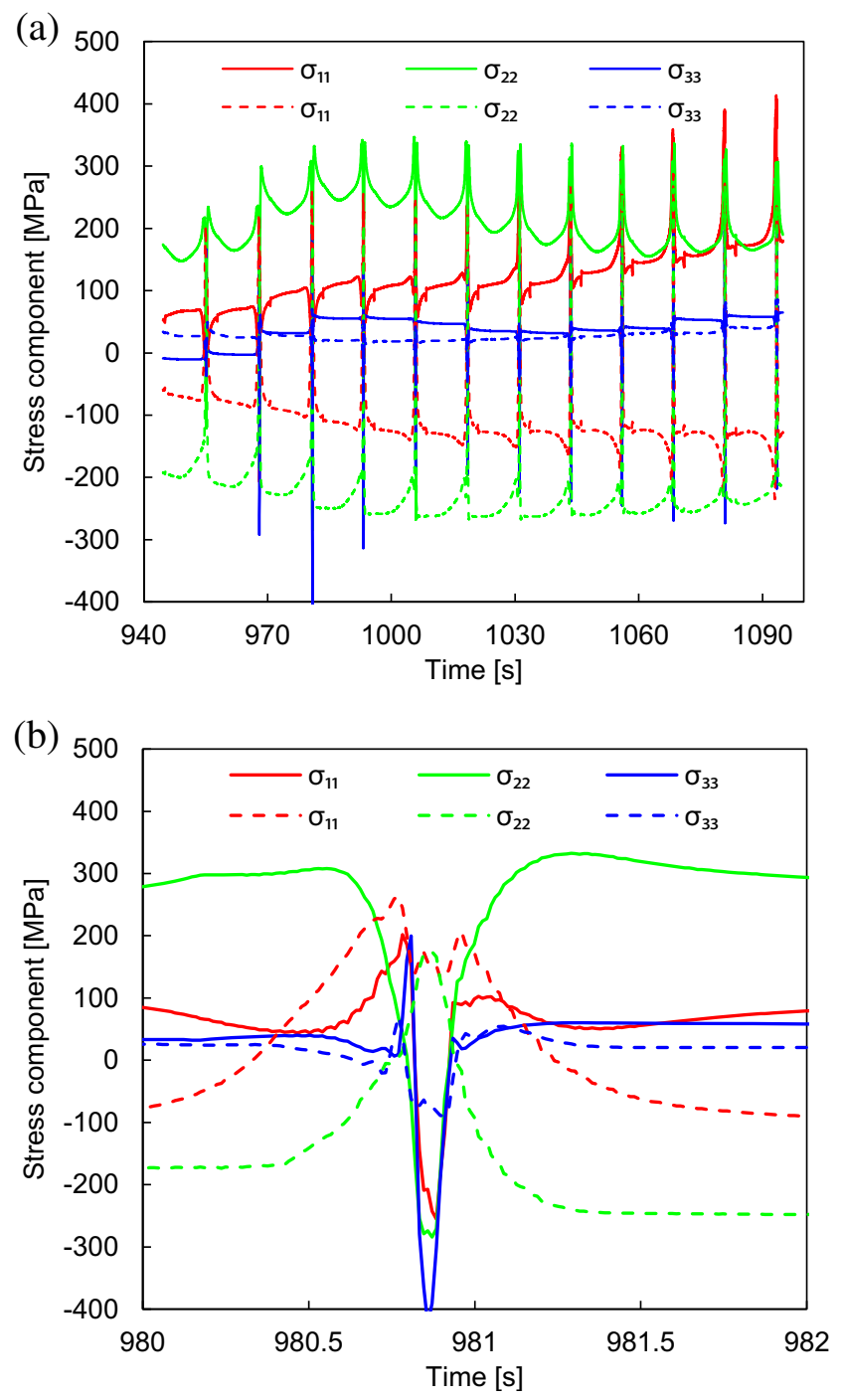

Fig. 21 Evolution of the stress components in the Gauss points GP1 U (solid line) and GP1_L (dashed line): a global overview for 12 circular contours; b detailed view when the tool passes exactly over the Gauss points and GP1_L (see Fig. 11). Since the deformation is confined to the vicinity of the contact area with the forming tool and the applied loading is cyclic as a result of the tool path, residual stresses are produced during the incremental forming, as shown in Fig. 21a. On the other hand, in order to highlight the characteristic stress state when the tool passes over the Gauss points under analysis, Fig. $21 \mathrm{~b}$ presents a detailed view of this instant. The stress components are denoted by solid line and dashed line for the Gauss point located near the upper surface (GP1_U) and near the lower surface (GP1_L), respectively.

Concerning the selected Gauss points (GP1_U and GP1_L) and the process interval analysed (12 circular contours), the residual stress components (meridional and circumferential) are positive (tension) in the inner skin of the cone and negative (compressive stress) in the outer skin, as shown in Fig. 21a. Furthermore, the residual stress component with larger magnitude arises in the circumferential direction [54] due to the restricted strain in this direction (see Fig. 17a). These results are in accordance with the experimental springback analysis performed by Dejardin et al. [55] in rings cut from the wall of the cone, noticing a negative elastic springback (closing of the ring) due to residual stresses (inner skin in tension and the outer skin in compression). Regarding the instant in which the forming
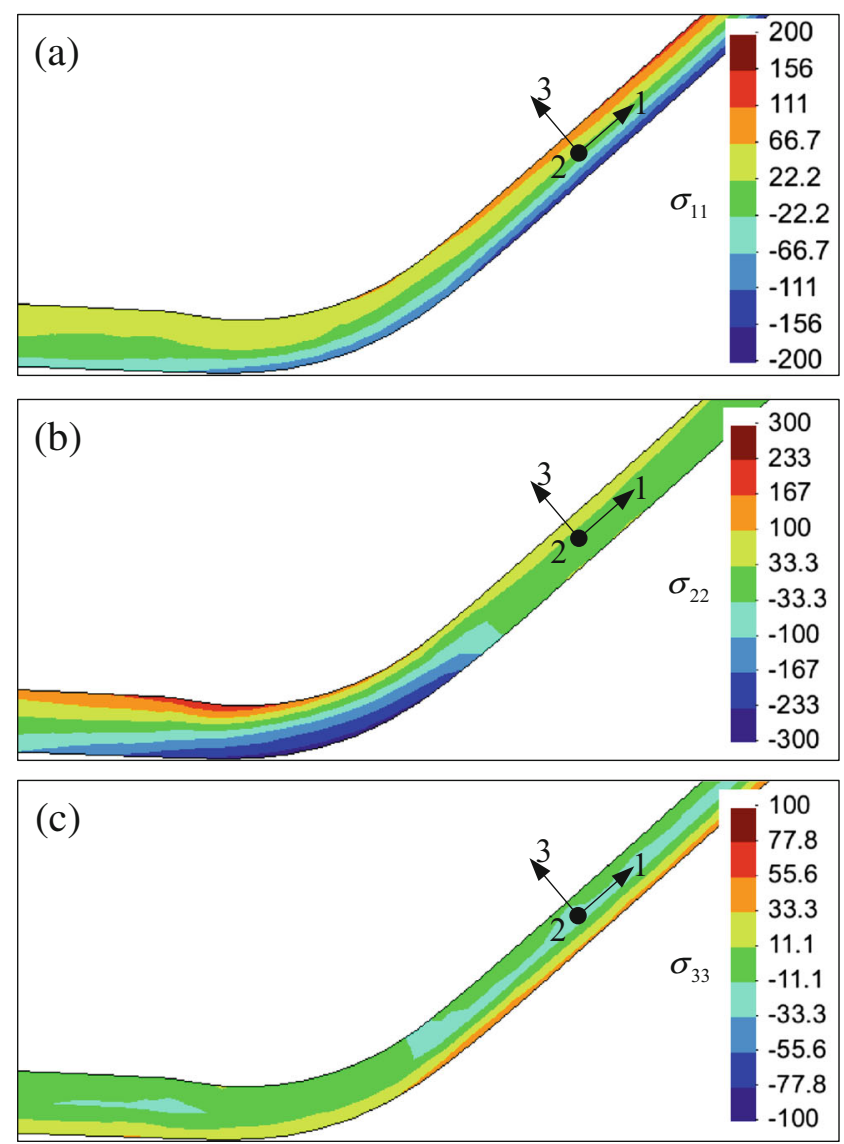

Fig. 22 Distribution of the stress components in the cross section of the cone aligned with the rolling direction for $983.6 \mathrm{~s}$ of forming process: a meridional direction; $\mathbf{b}$ circumferential direction; $\mathbf{c}$ thickness direction 
tool is just over the Gauss point GP1, the stress state is completely different, as highlighted in Fig. 21b. The thickness stress in the Gauss point close to the upper surface is negative (compression) due to the contact forces arising in the interface between the tool and the sheet. Furthermore, the other stress components (meridional and circumferential) are also compressive in this Gauss point under the tool, resulting from the bending effect. Therefore, a negative mean stress is generated in this localized area of the sheet due to the action of the tool on it, which is accompanied by a rise in the plastic strain (see Fig. 20). Since the mean stress is directly connected with the nucleation, growth and coalescence of microvoids in metallic sheets, the tool action postpones ductile fracture phenomenon [1].

The distribution of the residual stress components (meridional, circumferential and thickness) in the cross section of the truncated cone aligned with the rolling direction is presented in Fig. 22, for the instant preceding the downwards movement of the forming tool (983.6 s). The meridional stress is positive (tension) in the inner skin of the cone and negative (compression) in the outer skin, presenting higher magnitude in the already formed wall (cf., Fig. 21a) due to the unbending of sheet. On the other hand, the largest values (positive and negative) of circumferential stress arise in the vicinity of the contact area with the tool, as shown in Fig. 22b. Indeed, the circumferential stress is positive in the inner skin and negative in the outer skin, while the sign of this stress component switches when the tool passes over this cross section, as shown in Fig. 21b. Concerning the residual thickness stresses, they are negligible in the entire cross section (lower than $50 \mathrm{MPa}$ ), as shown in Fig. 22. Therefore, the residual stresses induced by the tool arise predominantly in the circumferential direction because circumferential strain is limited, while the deformation takes place mainly in the meridional direction.

\section{Conclusions}

The present study was undertaken with the objective to understand both the deformation mechanism and the stress state imposed on the material during the SPIF process. The truncated cone geometry of AA7075-O aluminium alloy, proposed as benchmark in the Numisheet 2014, was selected to validate the proposed finite element model. In order to evaluate accurately the $3 \mathrm{D}$ stress distribution under the forming tool, the blank is modelled with solid finite elements in conjunction with an implicit time integration scheme. Additionally, the numerical model takes into account the plastic anisotropy of the aluminium alloy, described by the Yld91 yield criterion.

The experimental forming force is slightly overestimated by the numerical model, which can result from the assumption of isotropic hardening in the mechanical behaviour of the sheet. On the other hand, the final thickness distribution of the truncated cone, predicted by the numerical simulation, is in very good agreement with the experimental measurements. Indeed, the thickness provided by the finite element simulation is considerably more accurate than the one calculated by the sine law. The comparison between experimental and numerical minormajor strain distribution, evaluated in the exterior surface of the cone, shows that the deformation mode is around plane strain condition. Both the minor and the major plastic strain distributions are accurately predicted by the numerical model, highlighting the strain path deviation towards biaxial stretching in the transition zone between the inclined wall and the bottom corner radius of the cone. Due to the action of the forming tool, a negative mean stress is generated in the vicinity of the contact area, postponing the ductile fracture by nucleation and growth of voids. In fact, the strain occurs mainly along the meridional direction because it is limited in the circumferential direction. Therefore, the residual stresses generated by the cyclic loading arise predominantly in the circumferential direction being positive in the inner skin and negative in the outer skin of the cone.

Acknowledgments The authors would like to gratefully acknowledge the financial support from the Portuguese Foundation for Science and Technology (FCT) under project PTDC/EMS-TEC/1805/2012. The first author is also grateful to the FCT for the postdoctoral grant SFRH/BPD/101334/2014.

\section{References}

1. Jeswiet J, Micari F, Hirt G et al (2005) Asymmetric single point incremental forming of sheet metal. CIRP Ann Manuf Technol 54: 88-114. doi:10.1016/S0007-8506(07)60021-3

2. Emmens WC, Sebastiani G, van den Boogaard AH (2010) The technology of incremental sheet forming - a brief review of the history. J Mater Process Technol 210:981-997. doi:10.1016/j. jmatprotec.2010.02.014

3. Echrif SBM, Hrairi M (2011) Research and progress in incremental sheet forming processes. Mater Manuf Process 26:1404-1414. doi: 10.1080/10426914.2010.544817

4. Meier H, Buff B, Laurischkat R, Smukala V (2009) Increasing the part accuracy in dieless robot-based incremental sheet metal forming. CIRP Ann Manuf Technol 58:233-238. doi:10.1016/j. cirp.2009.03.056

5. Filice L, Fratini L, Micari F (2002) Analysis of material formability in incremental forming. CIRP Ann Manuf Technol 51:199-202. doi:10.1016/S0007-8506(07)61499-1

6. Jeswiet J, Young D (2005) Forming limit diagrams for single-point incremental forming of aluminium sheet. Proc Inst Mech Eng B J Eng Manuf 219:359-364. doi:10.1243/095440505X32210

7. Essa K, Hartley P (2010) An assessment of various process strategies for improving precision in single point incremental forming. Int J Mater Form 4:401-412. doi:10.1007/s12289-010-1004-9

8. Micari F, Ambrogio G, Filice L (2007) Shape and dimensional accuracy in single point incremental forming: state of the art and future trends. J Mater Process Technol 191:390-395. doi:10.1016/j. jmatprotec.2007.03.066

9. Lasunon O, Knight WA (2007) Comparative investigation of single-point and double-point incremental sheet metal forming processes. Proc Inst Mech Eng B J Eng Manuf 221:1725-1732. doi:10. 1243/09544054JEM865 
10. Lu H, Kearney M, Li Y et al (2015) Model predictive control of incremental sheet forming for geometric accuracy improvement. Int J Adv Manuf Technol. doi:10.1007/s00170-015-7431-5

11. Rauch M, Hascoet J-Y, Hamann J-C, Plenel Y (2009) Tool path programming optimization for incremental sheet forming applications. Comput Aided Des 41:877-885. doi:10.1016/j.cad.2009.06.006

12. Hirt G, Ames J, Bambach M, Kopp R (2004) Forming strategies and process modelling for CNC incremental sheet forming. CIRP Ann Manuf Technol 53:203-206. doi:10.1016/S0007-8506(07)60679-9

13. Azaouzi M, Lebaal N (2012) Tool path optimization for single point incremental sheet forming using response surface method. Simul Model Pract Theory 24:49-58. doi:10.1016/j.simpat.2012.01.008

14. Mohammadi A, Vanhove H, Van Bael A, Duflou JR (2014) Towards accuracy improvement in single point incremental forming of shallow parts formed under laser assisted conditions. Int J Mater Form. doi:10.1007/s12289-014-1203-x

15. Duflou JR, Callebaut B, Verbert J, De Baerdemaeker H (2008) Improved SPIF performance through dynamic local heating. Int $\mathrm{J}$ Mach Tools Manuf 48:543-549. doi:10.1016/j.ijmachtools.2007. 08.010

16. Duflou J, Tunçkol Y, Szekeres A, Vanherck P (2007) Experimental study on force measurements for single point incremental forming. J Mater Process Technol 189:65-72. doi:10.1016/j.jmatprotec. 2007.01.005

17. Durante M, Formisano A, Langella A, Capece Minutolo FM (2009) The influence of tool rotation on an incremental forming process. J Mater Process Technol 209:4621-4626. doi:10.1016/j.jmatprotec. 2008.11.028

18. Durante M, Formisano A, Langella A (2010) Observations on the influence of tool-sheet contact conditions on an incremental forming process. J Mater Eng Perform 20:941-946. doi:10.1007/ s11665-010-9742-x

19. Aerens R, Eyckens P, Van Bael A, Duflou JR (2009) Force prediction for single point incremental forming deduced from experimental and FEM observations. Int J Adv Manuf Technol 46:969-982. doi:10.1007/s00170-009-2160-2

20. Li Y, Liu Z, Lu H et al (2014) Efficient force prediction for incremental sheet forming and experimental validation. Int J Adv Manuf Technol 73:571-587. doi:10.1007/s00170-014-5665-2

21. Fiorentino A (2013) Force-based failure criterion in incremental sheet forming. Int J Adv Manuf Technol 68:557-563. doi:10. 1007/s00170-013-4777-4

22. Lu B, Fang Y, Xu DK et al (2014) Mechanism investigation of friction-related effects in single point incremental forming using a developed oblique roller-ball tool. Int J Mach Tools Manuf 85:14 29. doi:10.1016/j.jimachtools.2014.04.007

23. Lu B, Ou H, Shi SQ et al (2014) Titanium based cranial reconstruction using incremental sheet forming. Int J Mater Form. doi:10. 1007/s12289-014-1205-8

24. Jackson K, Allwood J (2009) The mechanics of incremental sheet forming. J Mater Process Technol 209:1158-1174. doi:10.1016/j. jmatprotec.2008.03.025

25. Lu B, Fang Y, Xu DK et al (2015) Investigation of material deformation mechanism in double side incremental sheet forming. Int J Mach Tools Manuf 93:37-48. doi:10.1016/j.ijmachtools.2015.03.007

26. Yamashita M, Gotoh M, Atsumi S-Y (2008) Numerical simulation of incremental forming of sheet metal. J Mater Process Technol 199:163-172. doi:10.1016/j.jmatprotec.2007.07.037

27. Eyckens P, Belkassem B, Henrard C et al (2010) Strain evolution in the single point incremental forming process: digital image correlation measurement and finite element prediction. Int J Mater Form 4: 55-71. doi:10.1007/s12289-010-0995-6

28. Smith J, Malhotra R, Liu WK, Cao J (2013) Deformation mechanics in single-point and accumulative double-sided incremental forming. Int J Adv Manuf Technol 69:1185-1201. doi:10.1007/ s00170-013-5053-3
29. Silva MB, Skjoedt M, Bay N, Martins PAF (2009) Revisiting single-point incremental forming and formability/failure diagrams by means of finite elements and experimentation. J Strain Anal Eng Des 44:221-234. doi:10.1243/03093247JSA522

30. Bambach M (2014) Fast simulation of incremental sheet metal forming by adaptive remeshing and subcycling. Int J Mater Form. doi:10.1007/s12289-014-1204-9

31. Ben Ayed L, Robert C, Delamézière A et al (2014) Simplified numerical approach for incremental sheet metal forming process. Eng Struct 62-63:75-86. doi:10.1016/j.engstruct.2014.01.033

32. Elford M, Saha P, Seong D et al (2013) Benchmark 3 - incremental sheet forming. AIP Conf Proc 1567:227-261. doi:10.1063/1. 4849983

33. Menezes LF, Teodosiu C (2000) Three-dimensional numerical simulation of the deep-drawing process using solid finite elements. J Mater Process Technol 97:100-106. doi:10.1016/S0924-0136(99) 00345-3

34. Oliveira MC, Alves JL, Menezes LF (2008) Algorithms and strategies for treatment of large deformation frictional contact in the numerical simulation of deep drawing process. Arch Comput Methods Eng 15:113-162. doi:10.1007/s11831-008-9018-x

35. Alart P, Curnier A (1991) A mixed formulation for frictional contact problems prone to Newton like solution methods. Comput Methods Appl Mech Eng 92:353-375. doi:10.1016/0045-7825(91)90022-X

36. Menezes LF, Neto DM, Oliveira MC, Alves JL (2011) Improving computational performance through HPC techniques: case study using DD3IMP in-house code. AIP Conf Proc 1353:1220-1225. doi:10.1063/1.3589683

37. Neto DM, Oliveira MC, Menezes LF, Alves JL (2014) Applying Nagata patches to smooth discretized surfaces used in 3D frictional contact problems. Comput Methods Appl Mech Eng 271:296-320. doi:10.1016/j.cma.2013.12.008

38. Neto DM, Oliveira MC, Menezes LF, Alves JL (2013) Nagata patch interpolation using surface normal vectors evaluated from the IGES file. Finite Elem Anal Des 72:35-46. doi:10.1016/j.finel.2013.03. 004

39. Hughes TJR (1980) Generalization of selective integration procedures to anisotropic and nonlinear media. Int J Numer Methods Eng 15:1413-1418. doi:10.1002/nme.1620150914

40. Barlat F, Lege DJ, Brem JC (1991) A six-component yield function for anisotropic materials. Int J Plast 7:693-712. doi:10.1016/07496419(91)90052-Z

41. Hosford WF (1972) A generalized isotropic yield criterion. J Appl Mech 39:607. doi:10.1115/1.3422732

42. Filice L, Ambrogio G, Micari F (2006) On-line control of single point incremental forming operations through punch force monitoring. CIRP Ann Manuf Technol 55:245-248. doi:10.1016/S00078506(07)60408-9

43. Flores P, Duchene L, Bouffioux C et al (2007) Model identification and FE simulations: effect of different yield loci and hardening laws in sheet forming. Int J Plast 23:420-449. doi:10.1016/j.jplas.2006. 05.006

44. Li Y, Daniel WJT, Liu Z et al (2015) Deformation mechanics and efficient force prediction in single point incremental forming. $\mathrm{J}$ Mater Process Technol 221:100-111. doi:10.1016/j.jmatprotec. 2015.02.009

45. Khan MS, Coenen F, Dixon C et al (2014) An intelligent process model: predicting springback in single point incremental forming. Int J Adv Manuf Technol 76:2071-2082. doi:10.1007/s00170-0146431-1

46. Duflou JR, Vanhove H, Verbert J et al (2010) Twist revisited: twist phenomena in single point incremental forming. CIRP Ann Manuf Technol 59:307-310. doi:10.1016/j.cirp.2010.03.018

47. Wu SH, Reis A, Andrade Pires FM et al (2012) Study of tool trajectory in incremental forming. Adv Mater Res 472-475:15861591. doi:10.4028/www.scientific.net/AMR.472-475.1586 
48. Avitzur B, Yang CT (1960) Analysis of power spinning of cones. J Eng Ind 82:231. doi:10.1115/1.3663052

49. Young D, Jeswiet J (2004) Wall thickness variations in single-point incremental forming. Proc Inst Mech Eng B J Eng Manuf 218: 1453-1459. doi:10.1243/0954405042418400

50. Hussain G, Hayat N, Gao L (2008) An experimental study on the effect of thinning band on the sheet formability in negative incremental forming. Int J Mach Tools Manuf 48:1170-1178. doi:10. 1016/j.ijmachtools.2008.02.003

51. Skjoedt M, Hancock MH, Bay N (2007) Creating helical tool paths for single point incremental forming. Key Eng Mater 344: 583-590. doi:10.4028/www.scientific.net/KEM.344.583
52. Zhu H, Liu Z, Fu J (2010) Spiral tool-path generation with constant scallop height for sheet metal CNC incremental forming. Int J Adv Manuf Technol 54:911-919. doi:10.1007/s00170-010-2996-5

53. Hussain G, Gao L (2007) A novel method to test the thinning limits of sheet metals in negative incremental forming. Int J Mach Tools Manuf 47:419-435. doi:10.1016/j.ijmachtools.2006.06.015

54. Madeira T, Silva CMA, Silva MB, Martins PAF (2015) Failure in single point incremental forming. Int J Adv Manuf Technol. doi:10. 1007/s00170-014-6381-7

55. Dejardin S, Thibaud S, Gelin JC, Michel G (2010) Experimental investigations and numerical analysis for improving knowledge of incremental sheet forming process for sheet metal parts. J Mater Process Technol 210:363-369. doi:10.1016/j.jmatprotec.2009.09.025 